\title{
A Ornamentação na Viola da Gamba a partir da Visão de De
}

\section{Machy}

\author{
André Luiz Tartas | Universidade Federal do Paraná | Brasil \\ Silvana Ruffier Scarinci | Universidade Federal do Paraná | Brasil \\ Kristina Augustin | Universidade Federal Fluminense | Brasil
}

\begin{abstract}
Resumo: Neste artigo investigamos a ornamentação para viola da gamba a partir do livro Pièces de Violle en Musique et en Tablature (1685) de De Machy. A obra é o primeiro livro de peças para viola da gamba baixo publicado na França, e nela consta o Avertissement, um prefácio onde o autor expõe sua visão sobre o instrumento e propóe sinais de ornamentos. A ornamentação de De Machy será analisada considerando os pressupostos do Avertissement e o referencial teórico de autores do mesmo período. Com isso, buscamos oferecer subsídios para a compreensão e para a interpretação de sua obra.
\end{abstract}

Palavras-chave: De Machy, Ornamentação, Viola da Gamba, Música Antiga.

\begin{abstract}
In this article we investigate the ornamentation for viola da gamba from the book Pièces de Violle en Musique et en Tablature (1685) by De Machy. The work is the first book of pieces for viola da gamba bass published in France, and it contains the Avertissement, a preface where the author exposes his vision of the instrument and proposes signs of ornaments. De Machy's ornamentation will be analyzed considering the assumptions of the Avertissement and the theoretical framework of authors from the same period. With this, we seek to offer subsidies for the understanding and interpretation of his work.
\end{abstract}

Keywords: De Machy, Ornamentation, Viola da Gamba, Early Music. 


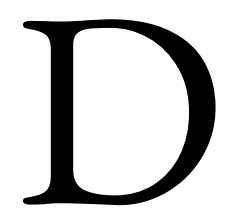

e Machy, também conhecido como Le Sieur de Machy ${ }^{1}$, nasceu em meados da segunda metade do século XVII, e foi um compositor e gambista que viveu durante o reinado do rei Luís XIV. Nascido em Abbeville, cidade localizada na região da Picardia, mudouse para Paris, e lá tornou-se aluno do gambista e teorbista Nicolas Hotman (ca. 1610-1663). Na capital francesa, dedicou-se ao ensino de viola da gamba no distrito de Fauxbourg St. Germain, na rua Neuve-des-Fossez (NG, 2008). São escassas as informações sobre a vida de De Machy; a sua data de nascimento, morte e mesmo o seu nome são desconhecidos.

De Machy foi o autor da primeira publicação impressa de peças para viola da gamba na França, o livro Pièces de Violle en Musique et en Tablature (1685). Em seu livro, ele expóe a sua visão sobre a viola da gamba, explicando questóes sobre o modo de tocar e pensar no instrumento. Sua obra foi criticada à época nas publicações de outros gambistas, e por algum tempo o seu nome não recebeu atenção por parte de pesquisadores e intérpretes. Porém pesquisas e gravações recentes têm contribuído para uma nova compreensão da sua obra.

FIGURA 1 - Primeira página do Pièces de Violle, conforme digitalização disponibilizada na Biblioteca Nacional Francesa, Gallica.

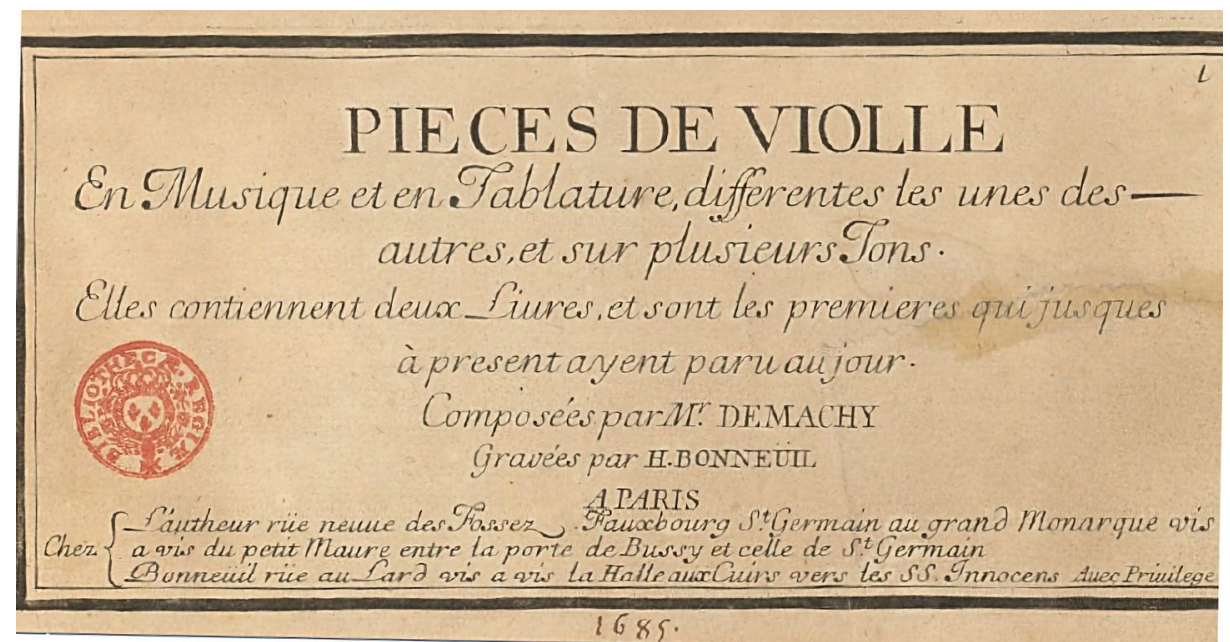

FONTE: BNF, Gallica (1685).

\footnotetext{
${ }^{1}$ Em relação à grafia do seu nome, na literatura é possível encontrar De Machy (KINNEY, 1976; SICARD, 1985; NG, (2008), Demachy (LESURE, 1960; HOFFMANN, 2018), DeMachy (CHENEY, 1988) e no dicionário Grove, Sieur de Machy é o verbete referente ao gambista (ROBINSON, Sieur de Machy, In: Grove Music Online). A capa de Pièces de Violle apresenta “Composées par Mr. DEMACHY”; entretanto optamos por manter a grafia De Machy, a mesma utilizada nas pesquisas de Kinney (1976) e NG (2008).
} 
A obra consiste em um Avertissement (prefácio) e oito suítes de danças divididos em dois livros; quatro peças escritas em partitura e quatro escritas em tablatura. As oito peças diferem entre si, porém foram separadas e escritas com notações diferentes com a finalidade de oferecer opções para o público que dominava a leitura em uma ou em outra notação. As composições contidas no livro Pièces de Violle são suítes de danças para viola da gamba solo, ou seja, sem acompanhamento, semelhantes àquelas compostas pelos alaudistas.

O prefácio (Avertissement) da obra em questão é um texto explicativo onde o autor revela a sua visão sobre o que considera ser a função adequada do instrumento, detalhando aspectos de como tocar, ensinar e escrever para ele. Um dos pontos criticados à época por Jean Rousseau (1644 - 1699) gambista e autor do Traité de la Viole (1687), foi a relação da viola da gamba com os instrumentos de cordas dedilhadas defendido por De Machy. Esse episódio ficou conhecido por Querelle ${ }^{2}$, e mostra as visôes divergentes sobre como tocar e compor para a viola da gamba.

De Machy defendia que a verdadeira natureza da viola da gamba é tocar peças harmônicas, com acordes (jeu d'harmonie) e semelhantes às cordas dedilhadas, diferente de Rousseau que defendia o jeu de melodie, estilo moldado na tradição vocal da chanson, e que devia ter na melodia sua principal característica. Além disso, outra característica que aproxima a viola da gamba dos instrumentos de cordas dedilhadas é o uso da tablatura, a mesma tablatura usada por alaudistas, teorbistas e guitarristas barrocos. De Machy foi único gambista francês que publicou suas composiçóes dessa maneira, e defendeu o seu uso por questões pedagógicas e interpretativas.

O uso da notação em tablatura não foi a única evidência da aproximação entre a viola da gamba e as cordas dedilhadas. Nesse sentido, a ornamentação que De Machy apresenta em seu Avertissement tem características utilizadas pelos instrumentistas de cordas dedilhadas. Alguns sinais de ornamentação criados por ele aparecem apenas em Pièces de Violle, e como não foram utilizados por outros gambistas e nem figuram em outras publicações, tendem a ser de difícil compreensão. Outra razão que confere complexidade a ornamentação de De Machy é o fato de requerer, por parte do intérprete, uma compreensão da técnica dos instrumentos de cordas dedilhadas.

A ornamentação é um dos importantes recursos que os músicos franceses utilizavam ao tocar

\footnotetext{
${ }^{2}$ Termo utilizado por François Lesure em artigo de 1960, e que a partir de então é empregado por outros musicólogos em seus escritos para descrever o episódio que envolveu os dois gambistas.
} 
ou compor no período barroco. A peculiaridade dos sinais de ornamentação de De Machy e a sua influência dos instrumentos de cordas dedilhadas fazem deste tema um objeto de análise relevante, principalmente no sentido de oferecer informações que podem contribuir para uma interpretação historicamente informada.

\section{A ornamentação na viola da gamba}

A ornamentação é considerada um dos principais aspectos da música francesa do século XVII e XVIII e uma das responsáveis por garantir o caráter, o estilo e a graça da música deste período (NG, 2008). Embora a importância da ornamentação seja consenso entre pesquisadores da área, os registros dos ornamentos para a viola da gamba começaram a aparecer em publicaçóes somente a partir da segunda metade do século XVII.

Os ornamentos específicos para a viola assim como seus símbolos e nomes ainda não estavam uniformizados no tempo de De Machy. Isso não significa que os gambistas não se utilizassem deste recurso expressivo e há motivos para acreditarmos que os ornamentos na viola da gamba eram “emprestados” dos instrumentos de cordas dedilhadas, principalmente do alaúde e teorba.

Devido à similaridade do braço da viola da gamba com o do alaúde, ambos dotados de trastes, unido ao fato de que muitos gambistas tocavam alaúde e vice-versa, é provável que tenha existido uma intensa interlocução relativa aos aspectos técnicos e ideias musicais em ambos os instrumentos. Acredita-se, portanto, que muitos dos ornamentos utilizados pelos gambistas tenham surgido a partir da ornamentação realizada pelos alaudistas.

No século XVII, a popularidade do alaúde na França foi determinante para o surgimento de várias publicaçôes e informaçôes acerca da ornamentação. Os compositores Ennemond Gaultier (1575-1651), Denis Gautier (1597 ou 1602-1672), Jaques Gallot (ca.1625-ca.1695), Charles Mouton (1626-1710) e Robert de Visée (ca.1655-1732/3) tiveram suas obras publicadas, e nelas foram utilizados símbolos e nomes para os ornamentos gerando uma certa uniformidade na grafia e uso, inspirando os gambistas e cravistas a buscarem também uma uniformização.

Apesar dos gambistas não terem tido muita conexão com os cravistas no que diz respeito a questôes técnicas e ornamentais, vale lembrar que os cravistas foram os primeiros a criar, organizar e 
publicar as Tabelas de Ornamentos (Table des Agréments) em meados do século XVII. Uma das primeiras tabelas foi a de Jacques Champion de Chambonnières (c. 1601/2 - 1672), na qual ele apresentou os ornamentos com seu nome, símbolo e abaixo de cada um a sua realização.

FIGURA 2 - Ornamentos do livro Les Pièces de Clavecin de Monsieur de Chambonnières, Livre Premier

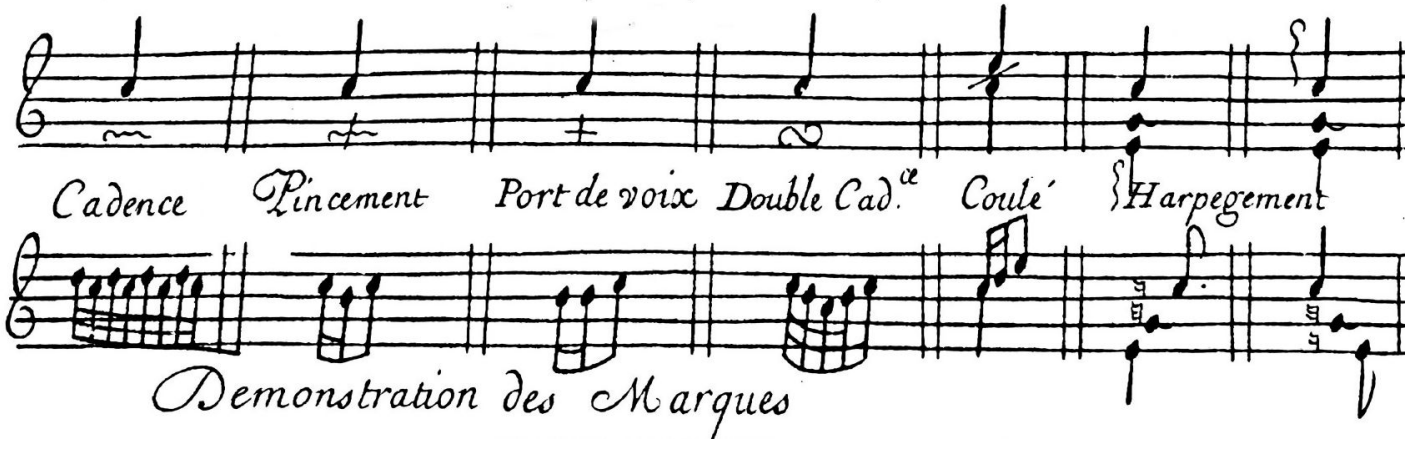

Fonte: CHAMBONNIÈRES (1670)

Essa forma didática e objetiva de exemplificar a ornamentação foi muito bem aceita pelos músicos e amantes da música na corte francesa, estimulando o surgimento de várias outras tabelas. É possível que De Machy tenha se inspirado nesse modelo para criar a tabela de ornamentos de seu livro, que pode ser considerada a mais complexa e abrangente tabela para viola da gamba. Gambistas anteriores como Nicolas Hotman (c.1610-1663), Du Buisson (1621/22-1680/81) e Sainte Colombe (fl 1658-87-c.1701) não deixaram registros sobre a ornamentação para a viola da gamba ou, se o fizeram, esses documentos não sobreviveram à ação do tempo para que tivéssemos acesso. Logo, o trabalho de De Machy continua sendo o primeiro registro comentado sobre ornamentação para viola da gamba na França.

\section{A ornamentação de De Machy}

De Machy transitou entre a viola da gamba e o alaúde e, assim como os gambistas da época, continuou a usar alguns sinais derivados da música para alaúde (GREEN, 1977). O seu círculo de amizades incluiu o já citado alaudista, teorbista e guitarrista barroco Robert de Visée com quem trocava informações segundo relatos de Rousseau. Foi a partir das técnicas adquiridas de seus colegas alaudistas que De Machy criou seus próprios sinais para ensinar ornamentação a seus alunos, de acordo com as concepçôes de que se praticava nas cordas dedilhadas: 
Com o conhecimento das práticas de outras tradições instrumentais, fica claro que o início da ornamentação na viola da gamba está profundamente enraizado nas práticas dos alaudistas do século XVII. A influência desses alaudistas, sem dúvida, abriu caminho para os gambistas incluírem suas ideias sobre ornamentação em suas composições. Por exemplo, no petit tremblement de De Machy, ele se refere a uma técnica no alaúde para demonstrar seu ornamento. Embora isso possa ser confuso para os gambistas atuais, seria instantaneamente entendido pelo gambista da época, muitos dos quais também eram alaudistas (NG, 2008, p. 104, tradução nossa).

Desde a publicação de Pièces de Violle de De Machy em 1685 até a publicação dos Pièces de Viole de Antoine Forqueray em 1745, todos os ornamentos da música francesa para viola da gamba foram cuidadosamente indicados nas partituras, embora nem sempre acompanhados de detalhes sobre a sua execução (GREEN, 1977). Em 1686, um ano após a publicação de De Machy, Marin Marais (16561728) teve seu primeiro livro publicado e em seu prefácio apresentou a descrição dos sinais utilizados por ele para os seus ornamentos ${ }^{3}$.

Comparado ao trabalho de De Machy, Marais diminuiu o número de sinais de ornamentação em seu livro de Pièces de Viole (1686) e apresentou de forma escrita os ornamentos antes marcados com símbolos. Essa ornamentação “por extenso”, diretamente no pentagrama musical, foi uma ruptura importante com a prática tradicional do alaúde (URQUHART, 1970).

As práticas de gambistas posteriores podem ter sido influenciadas por esse esforço inicial de De Machy. Por exemplo, embora Marais altere e reduza os símbolos usados em sua tabela de ornamentos e decida escrever por extenso a maioria de seus ornamentos, ele faz poucas adiçôes às idéias originais de De Machy. Ele apenas acrescenta o coulé de doigt, enflé e harpègement (NG, 2008, p. 104, tradução nossa).

Outras obras relevantes publicadas após 1685 são os tratados para viola da gamba de Rousseau e Danoville, ambas de 1687. Escritos poucos anos após a publicação do livro de De Machy e Marais, não incluíam as ideias semelhantes sobre ornamentação de seus antecessores. Logo, observa-se que desde o início das composições para viola da gamba solo francesas até as obras mais tardias, nenhum autor conseguiu padronizar os sinais de ornamentação para o instrumento.

Em geral, os compositores franceses não forneceram instruçóes suficientes para seus ornamentos, e não foi diferente entre os gambistas. A falta de explicações objetivas suscita, nos

\footnotetext{
${ }^{3}$ Para mais informações conferir a tradução comentada de Kristina Augustin dos prefácios dos cinco livros de Marin Marais. Disponível em https://www.nucleodoconhecimento.com.br/arte/marin-marais
} 
músicos de hoje, dúvidas sobre como realizar os ornamentos de acordo com o pensamento de seus criadores e intérpretes:

A variedade de diferentes sinais de ornamento (agréments) que os compositores franceses empregam em suas músicas pode ser uma fonte potencial de confusão para os músicos atualmente. Não apenas havia muitos sinais diferentes que representam o mesmo ornamento, mas também havia vários nomes diferentes para um único ornamento. Alguns compositores empregavam sinais familiares de ornamento sem maiores explicaçóes; apenas alguns compositores incluíram explicaçóes sobre como os sinais que usavam deveriam ser interpretados. Ainda adicionavam uma tabela de sinais de ornamento que se aplicavam à sua música. Outra fonte de confusão para os músicos de hoje surge do fato de que o ornamento que é essencialmente o mesmo, é marcado com um sinal diferente para a voz e para o cravo; os sinais de ornamento na música para viola da gamba solo também podem ser diferentes daqueles na música para violino (CYR, 2012, p. 107, tradução nossa, grifo nosso).

De Machy compreendeu essa necessidade de esclarecer os ornamentos. No Avertissement, o gambista mostra seu cuidado com um dos aspectos principais da música francesa instrumental apresentando, de maneira sem precedentes na literatura da viola da gamba, um texto e quadro com os ornamentos, abundantes em informaçôes, apesar de haver omitido como realizá-los (procedimento normal em todas obras semelhantes para o instrumento). Na tabela abaixo o gambista denomina onze tipos de ornamentos (números 1 ao 11) com instruções específicas de como executá-los ao longo de seu texto. Do número 13 ao 18 ele enumera aspectos técnicos sobre a mão esquerda e diferentes tipos de arcadas. Apesar de estarem incluídos no texto e tabela, não são considerados ornamentos.

FIGURA 3 - Quadro de ornamentos do Pièces de Violle

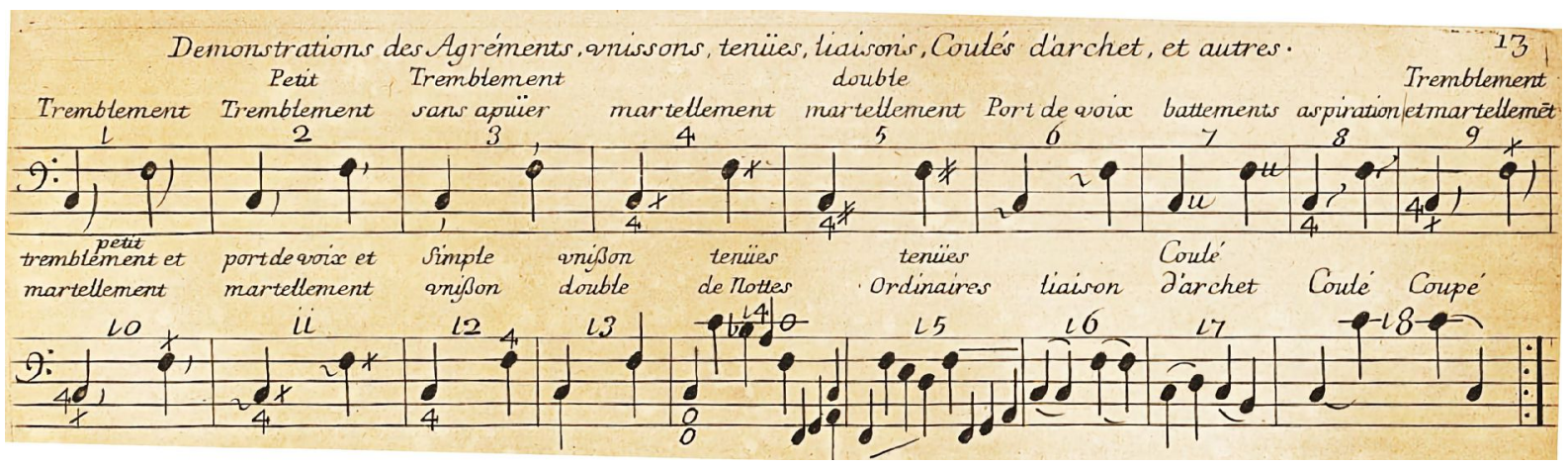

Fonte: DE MACHY (1685)

$\mathrm{Na}$ sequência, cada um dos ornamentos será detalhado e analisado a partir da visão de De Machy, encontrada no Avertissement de Pièces de Violle. Como nem todos ornamentos são de fácil 
compreensão e sua realização não está indicada pelo autor, buscamos analisar obras de outros gambistas, alaudistas, teorbistas, guitarristas barrocos e cravistas do período próximo à De Machy para exemplificar seus ornamentos.

\subsection{Tremblement}

FIGURA 4 - Recorte do ornamento simples número 1

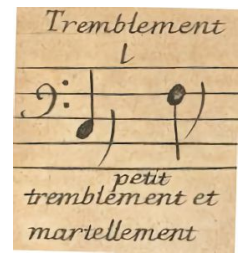

Fonte: DE MACHY (1685)

O tremblement [trilo] é possivelmente o ornamento mais comum na música francesa para viola da gamba desse período e encontra-se com muita frequência nas Pièces de Violle de De Machy. Diferente de outros compositores que especificaram um único tremblement, De Machy descreve três tipos; tremblement, petit tremblement e tremblement sans appuiër (sic). Tal sistema pode ocasionar confusões no momento de realizá-los, pois não encontramos em outros compositores para viola da gamba esses sinais, sendo necessário buscar informaçóes em tratados e composiçóes para outros instrumentos e para a voz.

O trilo é nomeado de outras maneiras em obras do período; Rousseau, por exemplo, denominao cadence: "O trinado tinha vários nomes diferentes, sendo os mais comuns tremblement ou cadence" (CYR, 2012, p. 107-108, tradução nossa). Quanto à utilização de sinais também havia diferentes formas de grafar: "Os símbolos mais comuns para o trinado na música de cordas eram uma cruz (+ ou $\times$ ) ou uma marca em zigue-zague horizontal. Na música para viola da gamba, em particular, uma vírgula imediatamente após a nota também foi usada para indicar um trinado” (Idem)

O tremblement nas pièces de De Machy é indicado por um sinal de vírgula grande e longo localizada após a nota. O autor descreve que "é necessário apoiar o tremblement segundo o valor da nota e o fazer igual” (DE MACHY, 1685, p. 8). Ao mencionar "apoiar”, De Machy refere-se a uma prática habitual da época, que era iniciar o ornamento a partir da nota superior à nota grafada na partitura e alternar essas duas notas de forma rápida, uniforme e regular, sem modificar o andamento. 
A explicação sobre qual a proporção da apojatura no início da nota principal não é clara. Portanto, a duração da apojatura dependerá do valor da nota à qual é aplicada, consequentemente notas mais longas exigirão uma apojatura mais longa e notas com duração mais curta terão sua apojatura com o valor reduzido, e suas oscilações deverão ser mais rápidas.

Quanto à regularidade do trinado, igualmente à sua denominação e duração da apojatura, os compositores franceses tanto de música instrumental quanto vocal apresentam ideias distintas. SaintLambert (fl. 1700) assim o descreveu: "é mais bonito tocá-lo lentamente primeiro e acelerá-lo no final” (SAINT-LAMBERT, 1702, p. 43, tradução nossa). A maneira como os cravistas realizavam os trilos provavelmente não era a mesma maneira dos gambistas, e autores para cordas dedilhadas trazem informações acerca desse ornamento com maior afinidade às ideias de De Machy. Jacques de Gallot, no "Méthode' de suas Pièces de Luth (Ca. 1684), recomendou o uso de "ritmos uniformes o mais rápido possível”, enquanto Jean Le Gallois (1632 - 1707) diz que “não há nada que faça tocar de forma mais amável... do que trinar igualmente e sustentar o trinado" (KAH-MING NG, Ornamentation, In: Grove Music Online, tradução nossa).

FIGURA 5 - Trinado no compasso 21 da allemande da II suite do primeiro livro

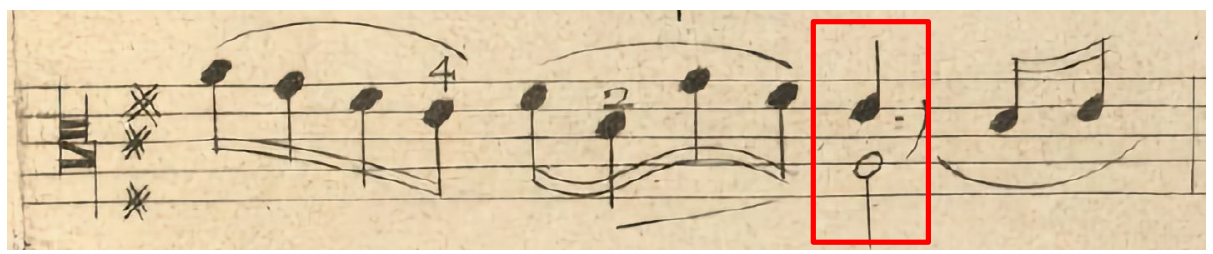

Fonte: DE MACHY (1685)

FIGURA 6 - Sugestão de realização do tremblement

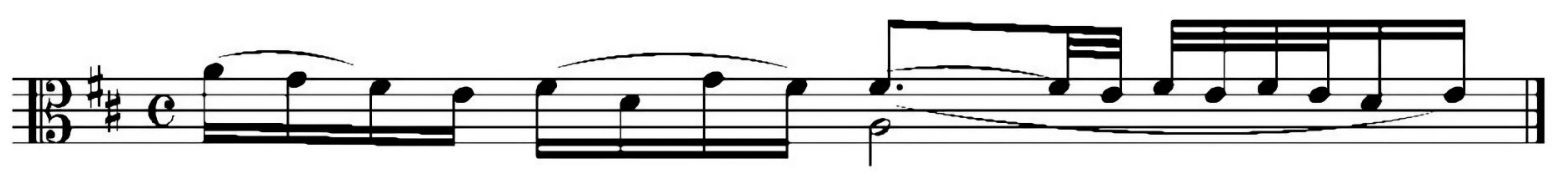

Fonte: O AUTOR (2020) 


\subsection{Petit Tremblement}

FIGURA 7 - Recorte do ornamento simples número 2

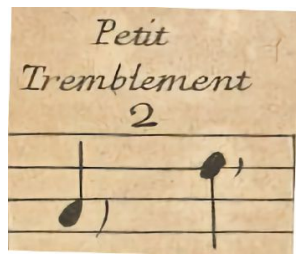

Fonte: DE MACHY (1685)

O petit tremblement é um outro tipo de trilo apresentado por De Machy: "o petit tremblement [pequeno trilo] que chamamos no alaúde de tiret, faz-se igual [que o tremblement] só que ele não é continuado” (DE MACHY, 1685, p. 8-9). Ele é representado por uma pequena vírgula após a nota.

A realização desse ornamento é descrita de diferentes formas por pesquisadores e gambistas. Mary Cyr descreve: "O trinado curto, geralmente composto de apenas quatro notas, foi tocado rapidamente e serve em muitos casos quando um ornamento era necessário em uma nota relativamente curta” (CYR, 2012, p. 109, tradução nossa). Ng (2008) conclui que o petit tremblement tem sua origem nos instrumentos de cordas dedilhadas, portanto realiza-se de forma semelhante, apenas toca-se a apojatura e não se repete as alternâncias de nota.

A alusão ao tiret do alaúde por De Machy na interpretação do petit tremblement, demonstra essa aproximação do vocabulário das cordas dedilhadas com a viola da gamba. Entretanto a realização do tiret pelo alaúde não corresponde exatamente o que acontece na viola da gamba: no alaúde o efeito de bater o dedo no traste puxando a corda com o próprio dedo permite que a nota inferior soe, e na viola da gamba não é necessário porque o som é sustentado pelo arco.

O alaudista Denis Gaultier afirma que uma vírgula após a letra (em tablatura) indica que: “é necessário puxar a corda com um dedo da mão esquerda”. Semelhantemente a essa recomendação, o alaudista Charles Mouton esclarece: "puxar a corda com a mão esquerda depois de tocá-la com a mão direita uma vez” (NG, 2008, p. 55, tradução nossa).

A falta de informaçóes necessárias para entendermos como realizar o petit tremblement pode ocasionar múltiplas maneiras de tocá-lo. Verifica-se, portanto, que pode haver diferentes interpretações por gambistas modernos para esse ornamento; a primeira sugestão foi escolhida por 
causa da possível aproximação de como ele é realizado pelas cordas dedilhadas, e a segunda sugestão trata-se de uma diminuição da quantidade de trilos, proposta por Cyr.

FIGURA 8 - Petit tremblement no compasso 3 da sarabande da III suite do primeiro livro

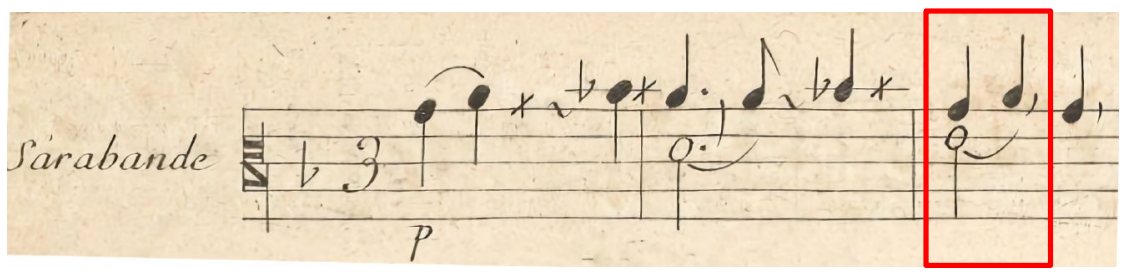

Fonte: DE MACHY (1685)

FIGURA 9 - Sugestão de realização do petit tremblement

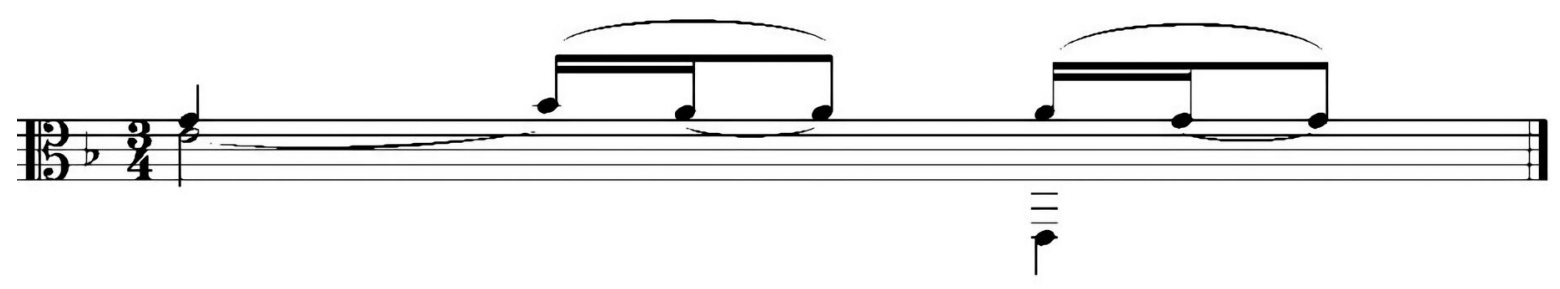

Fonte: O AUTOR (2020)

FIGURA 10 - Sugestão de realização do petit tremblement

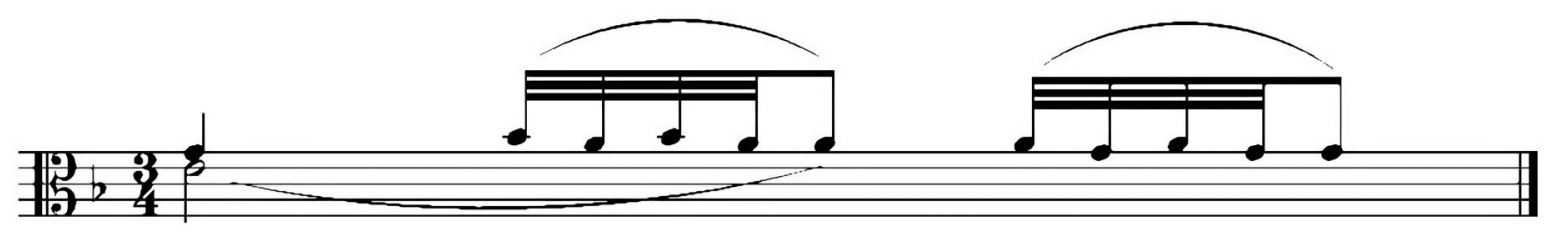

Fonte: O AUTOR (2020)

\subsection{Tremblement sans apuïer}

FIGURA 11 - Recorte do ornamento simples número 3

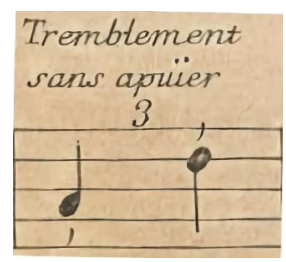

Fonte: DE MACHY (1685) 
O terceiro sinal apresentado por De Machy é o tremblement sans apuïer [trilo sem apoio]. É sinalizado por uma pequena vírgula localizada bem abaixo da nota ou acima da nota, diferente dos outros tremblements em que a vírgula se localiza ao lado das notas.

O efeito desse ornamento é de um vibrato mais intenso, no qual um dedo está pressionando o traste e o outro está tocando a corda repetidamente muito próximo ao primeiro dedo, ou seja, “[...] é semelhante a um trinado, exceto que o trilo do dedo, toca a corda tão levemente e tão perto do dedo abaixo dela que na verdade não altera o tom” (HOFFMAN, 2018, p. 250, tradução nossa).

Este ornamento é semelhante aos trilos por causa das repetições dos movimentos dos dedos, embora outros gambistas atribuam outros nomes para a ação similar, como Marais que o chama de pincé ou flatement. A maioria dos ornamentos apresentados por De Machy são compartilhados com as cordas dedilhadas, entretanto o tremblement sans apuier é um ornamento idiomático da viola da gamba: "Diferentemente da viola da gamba, que é um instrumento de arco, o alaúde não produz sustentação adequada para executar o ornamento; tocar a corda acima do traste apenas silenciaria o som” (NG, 2014, p. 60, tradução nossa).

Esse ornamento é pouco utilizado por De Machy e geralmente é aplicado em notas de longa duração.

FIGURA 12 - Tremblement sans apuïer no compasso 24 do double da III suíte

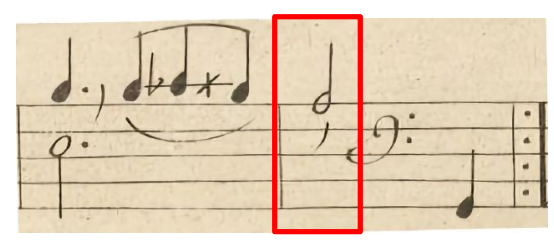

Fonte: O AUTOR (2020)

\subsection{Martellement e Double Martellement}

FIGURA 13- Recorte dos ornamentos simples número 4 e 5

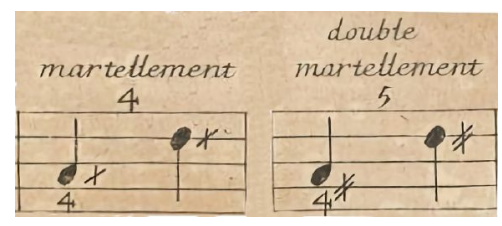

Fonte: DE MACHY (1685) 
O sinal de martellement utilizado por De Machy e alaudistas como Gallot, De Visée e Mouton é usado para representar o que hoje chamamos de mordente inferior. Em outras obras de autores franceses pode ser também denominado por battement (Marais), pince (Danoville), pincement (Chambonières).

O martellement é um dos ornamentos mais frequentes nas suítes de De Machy, assim como na música francesa do século XVII e XVIII, e sobre o seu efeito Rousseau afirmou que “(...) nunca pode ter um efeito ruim, exceto quando for muito frequente" (ROUSSEAU, 1687, p. 105). Em conjunto com o tremblement são os únicos que permanecem sem modificações na tabela de Marais.

Na música para alaúde o martellement é encontrado desde o início do século XVII, e De Machy utiliza o mesmo sinal que De Visée, o que demonstra que esse ornamento foi claramente assimilado pelos gambistas: “Os sinais utilizados por ambos [De Machy e Marais], para o trilo e o mordente, podem ser encontrados nas obras de compositores de alaúde e viola da gamba da França no século XVII, já na primeira década, por exemplo, nas obras de Le Vieux Gautier" (URQUHART, 1970, p. 97, tradução nossa).

Segundo De Machy, para a sua realização: “Le martellement deve-se levantar o dedo da nota ou da letra [se for tablatura] assim que ela é tocada e o recolocar imediatamente” (DE MACHY, 1685, p.9). O sinal usado é de um (x) localizado ao lado da nota.

Sobre o double martellement [mordente duplo] é feito igual [martellement simples], porém é realizado dobrado, duas vezes o mesmo efeito e é indicado pelo sinal $(\neq)$ após a nota.

A semelhança com o sinal de sustenido (\#) nas Pièces de Violle pode ocasionar equívocos, porém é necessário observar que o sinal do martellement nas suítes de De Machy se localizam após a nota e o sustenido antes.

FIGURA 14 - Martellement e double martellement no compasso 1 da allemande suíte II do segundo livro

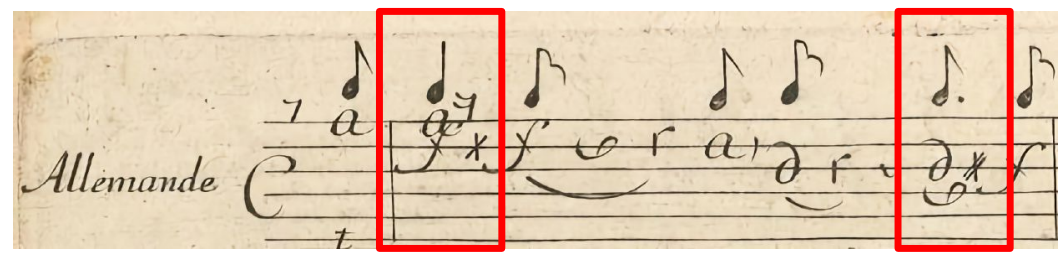

Fonte: DE MACHY (1685) 


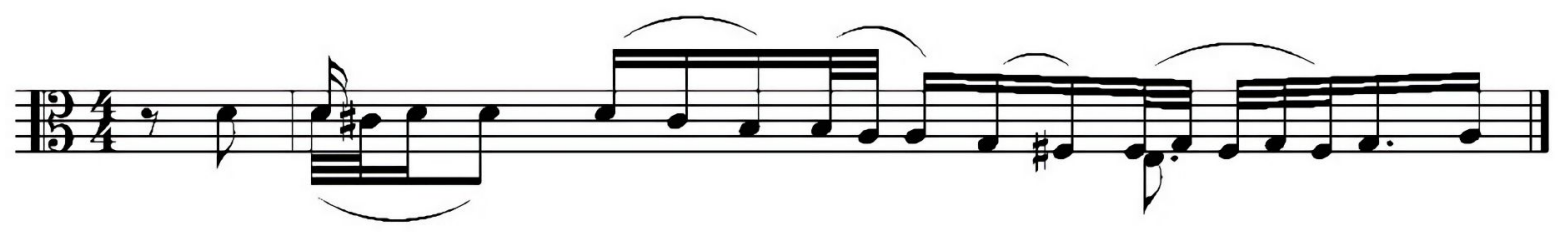

Fonte: O AUTOR (2020)

\subsection{Port de voix}

FIGURA 16- Recorte do ornamento simples número 6

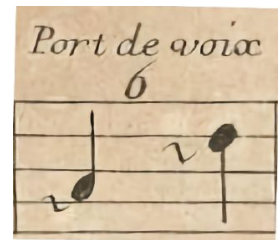

Fonte: DE MACHY (1685)

O port de voix é uma apojatura inferior que antecipa a nota principal e De Machy o representa com o sinal ( ) antes da nota. Segundo De Machy: "O port de voix [apojatura longa] que chamamos de cheutte no alaúde e outros instrumentos, é feita pela antecipação de uma nota ou letra [tablatura] (DE MACHY, 1685, p. 9, tradução nossa).

Instrumentistas e pesquisadores de hoje apontam que para De Machy o port de voix deve ser executado no tempo e não antes, e isso é revelado devido a sua proximidade com instrumentistas de cordas dedilhadas, fonte dos maneirismos que o gambista emprega em suas pièces. Assim como a viola da gamba, os autores das pièces de cravo também aplicaram técnicas das cordas dedilhadas: “[...] Chambonnières, ao transferir aspectos do estilo alaúde para o cravo, adotou procedimentos de ornamentação desse instrumento" (GREEN, 1977, p. 31).

De Machy no Avertissement refere-se à cheutte [sic], que é o termo utilizado por alaudistas para representar o port de voix: "Mouton e Gallot denominam a apojatura de chute quando antecipada por uma nota inferior e De Visée a chama de cheutes”(ROLFHANRE, 2010, p. 40). De Machy revela a origem da ideia desse ornamento, entretanto altera seu sinal para $(\sim)$ e o chama de port de voix, termo não encontrado na literatura das cordas dedilhadas. 
A maneira como Marais escreve o port de voix, com uma pequena nota ligada à nota principal resulta em uma realização igual à de De Machy e indica uma proximidade entre os gambistas, porém o sinal utilizado por De Machy os diferenciam. Abaixo, exemplos do port de voix de Marais e De Machy, embora grafados de maneira diferente o efeito obtido são o mesmo:

FIGURA 17 -Port de voix no compasso 7 na courante da página 17 do primeiro livro

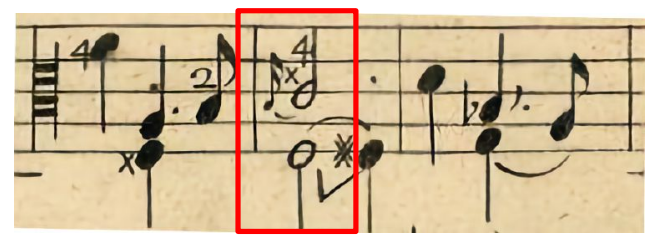

Fonte: MARAIS (1686)

FIGURA 18 -Port de voix no compasso 16 - menuet da suite I do segundo livro

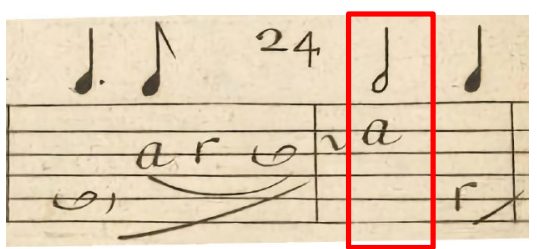

Fonte: DE MACHY (1685)

FIGURA 19 - Sugestão de realização do port de voix

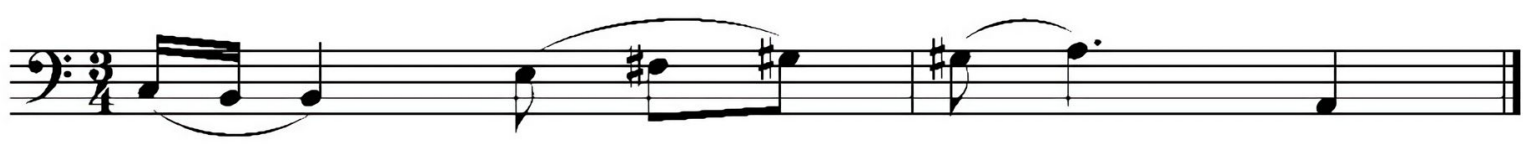

Fonte: O AUTOR (2020)

\subsection{Battement}

FIGURA 20 - Recorte do ornamento simples número 7

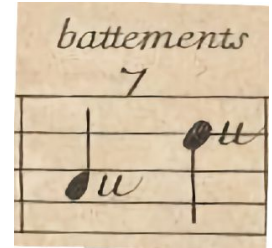

Fonte: DE MACHY (1685) 
Esse ornamento é na verdade um trilo que começa na nota principal e deve ser realizado como um tremblement sem apoggiatura. Em seu prefácio De Machy expóe: "o battement deve ser iniciado com o dedo levantado e continuar como o tremblement” (DE MACHY, 1685, p.9, tradução nossa). Esse ornamento é um vibrato raramente utilizado por De Machy, encontrado somente na tablatura.

FIGURA 21 - Battement no compasso 2 da allemande da I suíte do segundo livro

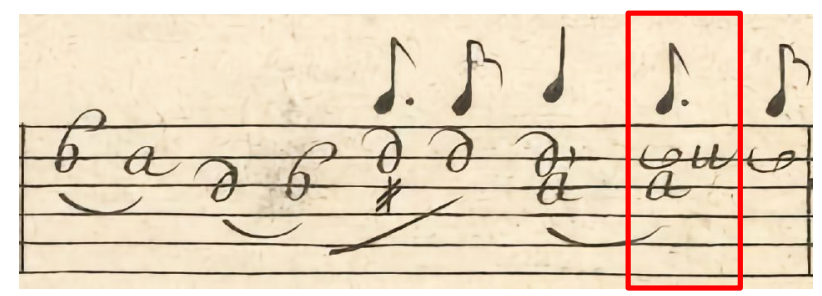

Fonte: DE MACHY (1685)

\subsection{Aspiration}

FIGURA 22 - Recorte do ornamento simples número 8

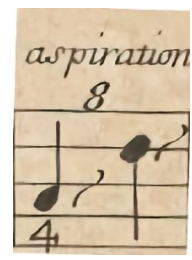

Fonte: DE MACHY (1685)

Segundo De Machy: "a aspiration, que também é chamada de plainte, se faz oscilando o dedo no traste” (DE MACHY, 1685, p.9). Esse ornamento é semelhante a dois outros efeitos que lembram o vibrato já descritos por De Machy, o tremblement sans apü̈er e o battement, com a diferença de ser indicado para ser tocado sempre com o quarto dedo. Verificamos ainda a referência ao som do miado do gato, De Machy escreveu: "há pessoas que querem chamar isso de miaullement [miau] por alusão [ao gato]" (DE MACHY, 1685, p.9). Encontramos na obra para guitarra barroca de De Visée (1686) o ornamento moillement (vibrato), que indica a proximidade entre os músicos devido à semelhança nos nomes dados. 


\section{FIGURA 23 - Ornamento miolement do livre de pièces pour guittarre de De Viseè}

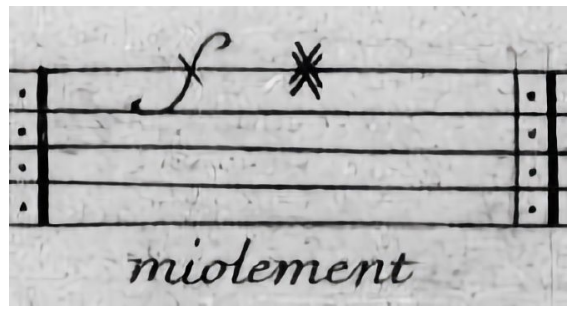

Fonte: DE VISÉE (1686)

Danoville e Marais o chamavam também de balancement e plainte, nesta ordem, e usaram em suas obras descrições parecidas para o ornamento: "o balancement de main de Danoville provavelmente corresponde ao plainte de Marais porque suas explicações para o ornamento são semelhantes: os dois compositores usam o mesmo verbo balançar em suas descrições” (NG, 2014, p. 65).

O próprio De Machy reconhece o termo plainte utilizado por Marais para descrever o ornamento, o que possibilita uma aproximação de suas ideias para o ornamento. Danoville que descreveu as realizaçôes de alguns de seus ornamentos, infelizmente deixou-o de fora, inviabilizando uma possível fonte para tocá-lo conforme os gambistas da época.

É comum encontrarmos o ornamento aspiration de De Machy com o nome de plainte ou balancement, eles provavelmente descrevem o mesmo efeito, porém encontramos outros sinais para o ornamento em obras de outros compositores. Etienne Loulié $(1654$ - 1702) descreve em seu manuscrito sobre viola da gamba (inacabado devido a sua morte) que: "o balancement são duas ou mais pequenas aspirations suaves e lentas que são [tocadas] em uma nota sem alterar seu tom" (LOULIÉ, [17- ? ], p. 73). A descrição de Loulié é bastante próxima à de De Machy, o que nos faz acreditar que sua realização pode ser igual a encontrada no manuscrito abaixo: 
FIGURA 24 - Realização do balancement segundo Loulié

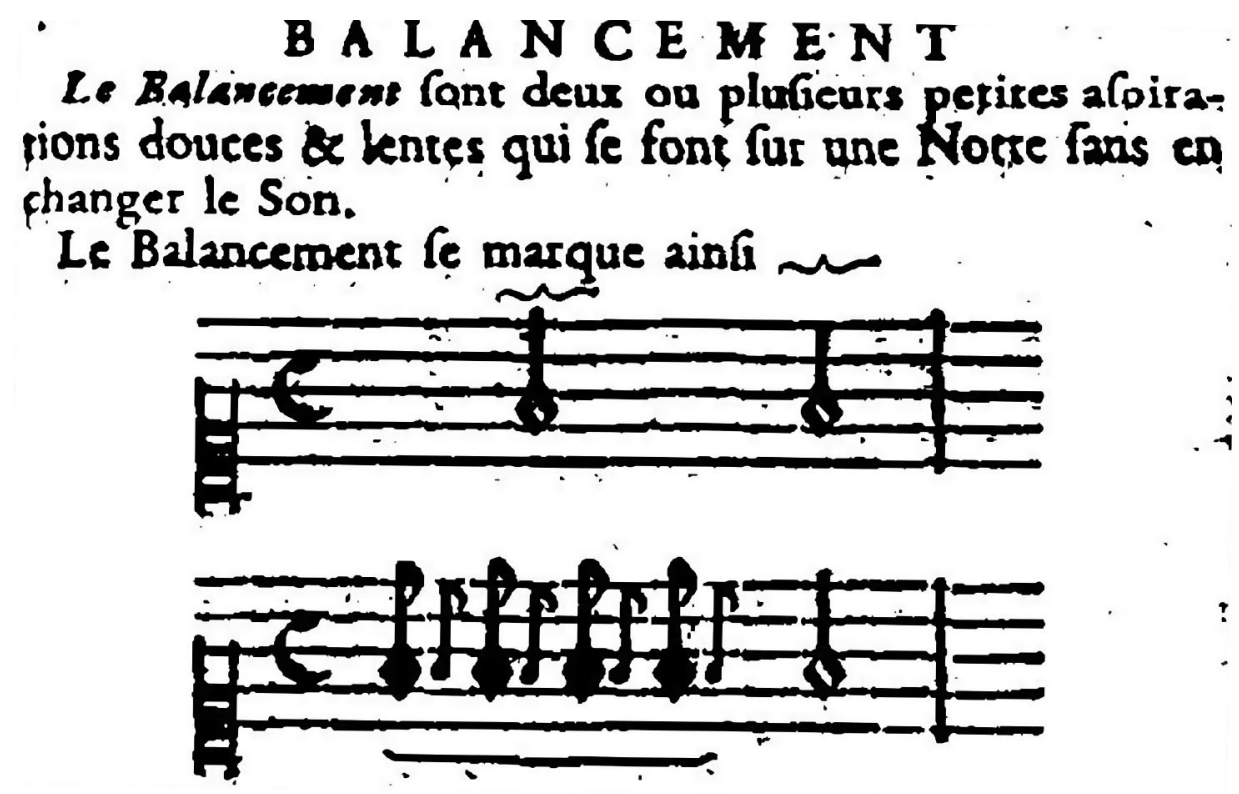

Fonte: NG (2014)

Os três próximos ornamentos apresentados por De Machy são ornamentos compostos, formado pela mistura de dois símbolos. No dizer de NG: "De Machy é o único gambista a combinar ornamentos. Isso torna a interpretação desses ornamentos um pouco mais complicada, pois não há ornamentos semelhantes de outros compositores de viola da gamba da época para serem usados como modelo para eles" (NG, 2008, p. 93).

Os ornamentos compostos a que se refere $\mathrm{Ng}$ (2008) possuem nomes também compostos, que indicam uma combinação, e são eles o tremblement et martellement, petit tremblement et martellement $\mathrm{e}$ port de voix et martellement.

\subsection{Tremblement et martellement}

FIGURA 25 - Recorte do ornamento composto número 9

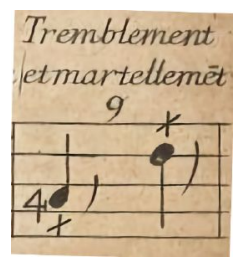

Fonte: DE MACHY (1685) 
No caso do ornamento composto tremblement et martellement, primeiro se executa o trilo, grafado pela grande virgula, seguido pelo mordente sinalizado pelo (x). De Machy explica: "Quando um martellement está com o tremblement, o petit tremblement, ou o port de voix, sempre deve-se começar a tocar pelo último sinal” (DE MACHY, 1685, p. 9).

FIGURA 26 - Tremblement et martellement no compasso 27 do menuet do suíte I do segundo livro

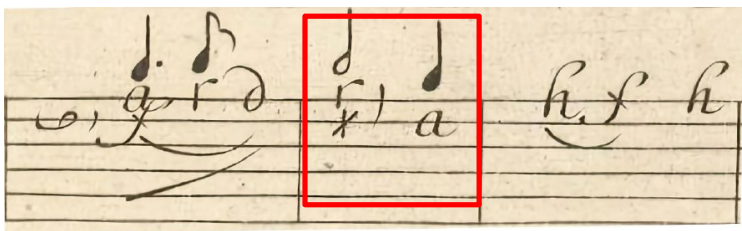

Fonte: DE MACHY (1685)

FIGURA 27 -Sugestão de realização do tremblement et martellement

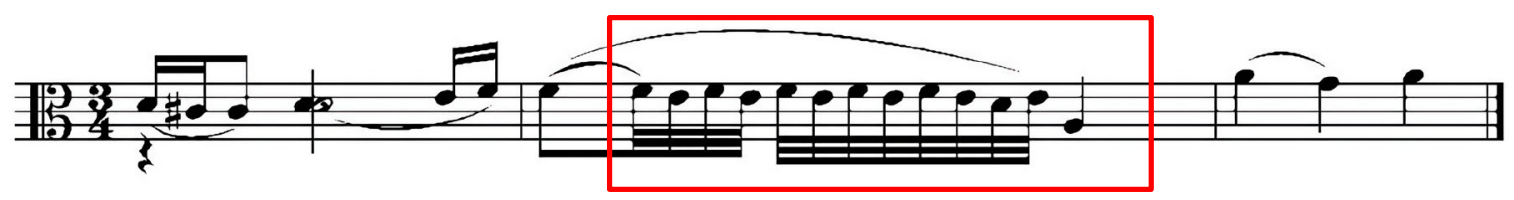

Fonte: O AUTOR (2020)

\subsection{Petit tremblement et martellement}

FIGURA 28 - Recorte do ornamento composto número 10

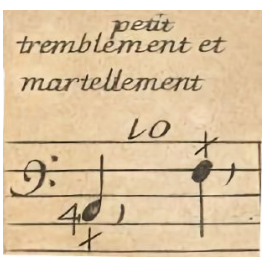

Fonte: DE MACHY (1685)

Este é um ornamento bastante recorrente nas peças de compositores da época de De Machy, no entanto, outros gambistas como Marais marcavam em suas partituras de forma escrita (petites nottes perdües). Para tocar esse ornamento é preciso realizar o petit tremblement (apojatura da nota superior), seguido do martellement (mordente rápido da nota inferior). 
Seguimos neste ornamento a ideia do petit tremblement, com apenas uma apojatura e sem continuação do trilo, da mesma forma como o tiret das cordas dedilhadas.

FIGURA 29 - Petit tremblement et martellement no compasso 17 da allemande suíte I do primeiro livro

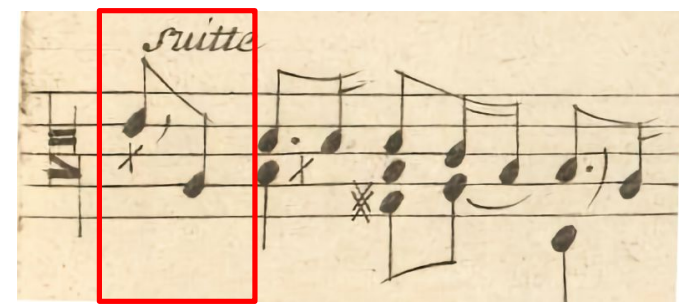

Fonte: DE MACHY (1685)

FIGURA 30 - Sugestão de realização do petit tremblement et martellement

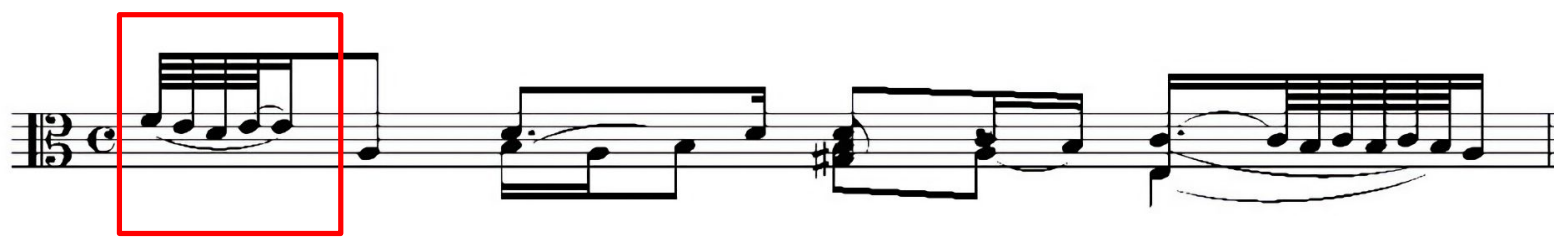

Fonte: O AUTOR (2020)

\subsection{Port de voix et martellement}

FIGURA 31 - Recorte do ornamento composto número 11

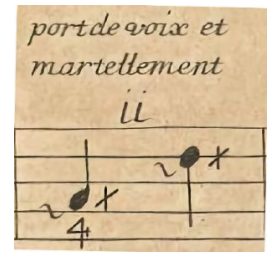

Fonte: DE MACHY (1685)

Esta combinação de ornamentos está presente em muitas passagens da música de De Machy, e muitos gambistas utilizavam desse recurso. Rousseau o descreve: "o martellement é sempre inseparável do port de voix, porque o port de voix deve sempre terminar com um martellement" (ROUSSEAU, 1687, p. 87). Marais também utilizou a mesma ideia que De Machy, com a diferença de que no seu livro o port de voix é representado por uma colcheia ou semicolcheia ligada à nota principal. 
FIGURA 32 - Port de voix et batement no compasso 10 do menuet do primeiro livro de pièces de violle

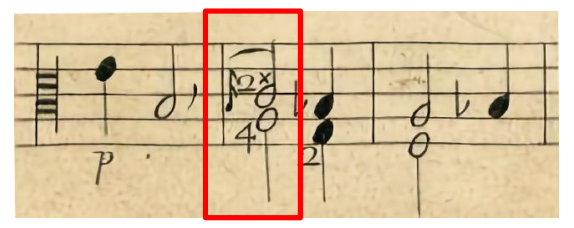

Fonte: MARAIS (1686, p. 30)

De Machy representa o port de voix et martellement pelo sinal ( ) anterior à nota principal e o sinal (x) na sequência. Ele consiste em uma apojatura inferior da nota principal, seguido por um mordente. Nos exemplos, acima o de Marais e abaixo o de De Machy, observamos a mesma ideia em que cada compositor representou à sua maneira.

FIGURA 33 - Port de voix et martellement no compasso 17 da sarabande da suíte I do segundo livro

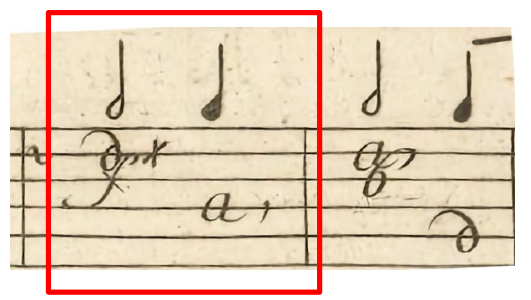

Fonte: DE MACHY (1685)

FIGURA 34 - Sugestão de realização do port de voix et martellement

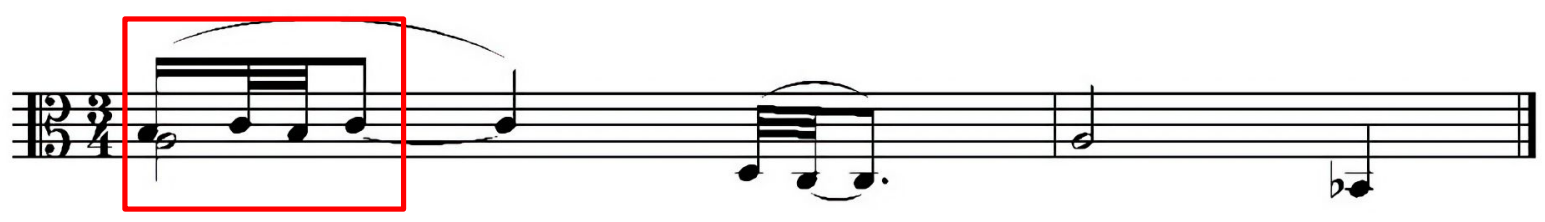

Fonte: O AUTOR (2020)

Apesar de termos exemplos onde pesquisadores comentam a ornamentação de De Machy, poucos se arriscaram em descrever sua realização. A estranheza de alguns sinais requer um maior aprofundamento e conhecimento de como alaudistas, guitarristas barrocos e teorbistas realizam a ornamentação, dada a relação do autor com estes instrumentos.

Além disso, à época era comum encontrar nomes diferentes para um mesmo tipo de ornamento. Hans Bol (1976) mostra os seguintes nomes para designar, na música francesa, a 
apojatura inferior: "Accent plaintif, Accent, Chute, Port de voix (en montant), Appoggiature ascendante" e para a superior: "Chute, Cheute, Coulé, Port de voix en descendant, Appoggiature descendante" (BOL, 1976, p. 19, apud NG, 2014, tradução nossa).

Nos instrumentos de cordas dedilhadas e na viola da gamba, é possível também verificar nomes diferentes para sinais de ornamentos com funçôes semelhantes. Por esse motivo, apresentamos abaixo uma tabela elaborada a partir de De Machy, que busca relacionar os ornamentos do autor com os sinais das cordas dedilhadas de Visée e Gaultier e os utilizados por Marais, com a finalidade de ressaltar a semelhança entre eles:

QUADRO 1 - Comparação entre os ornamentos De Machy, Visée e Gautier e Marais

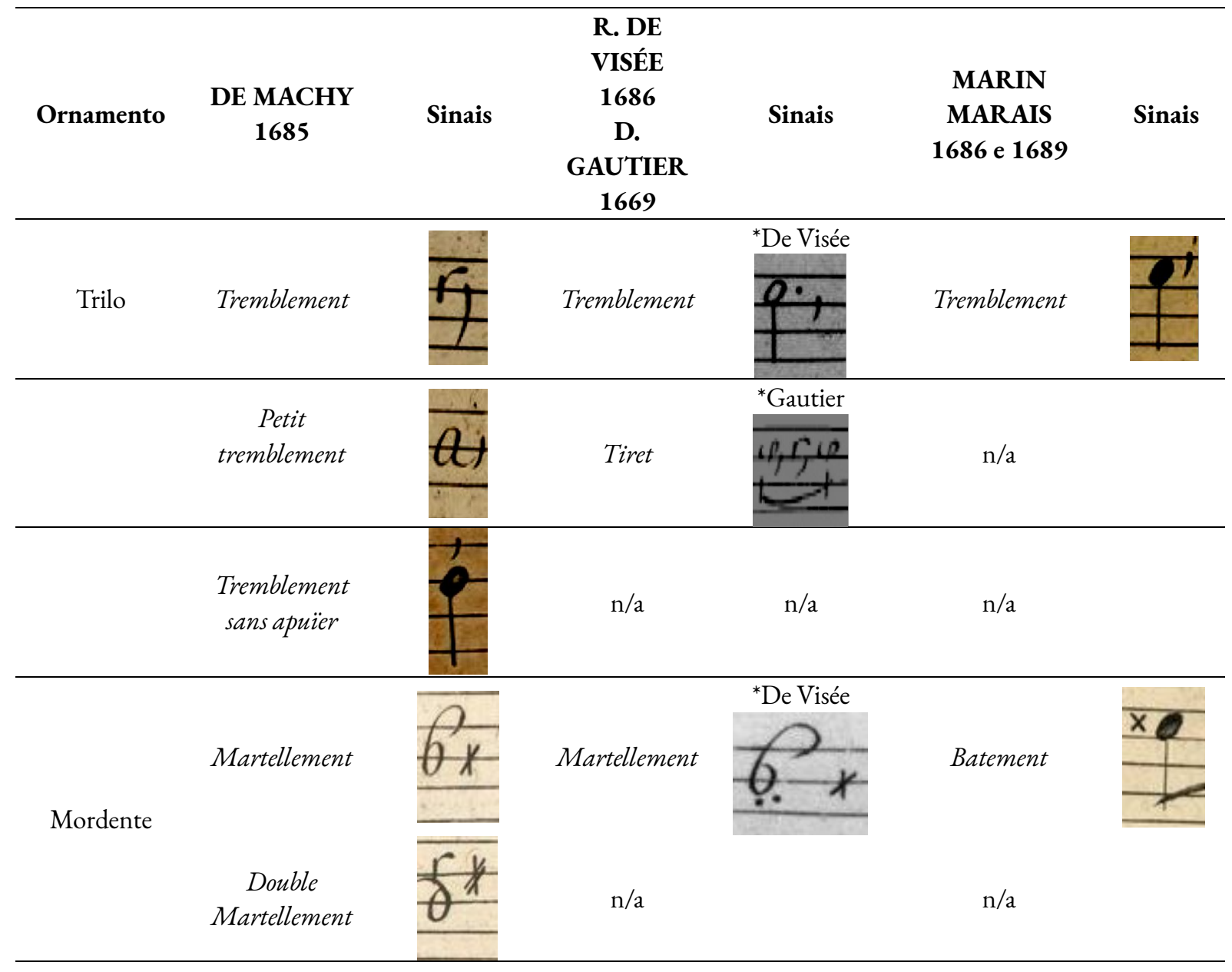


QUADRO 1 (cont.) - Comparação entre os ornamentos De Machy, Visée e Gautier e Marais

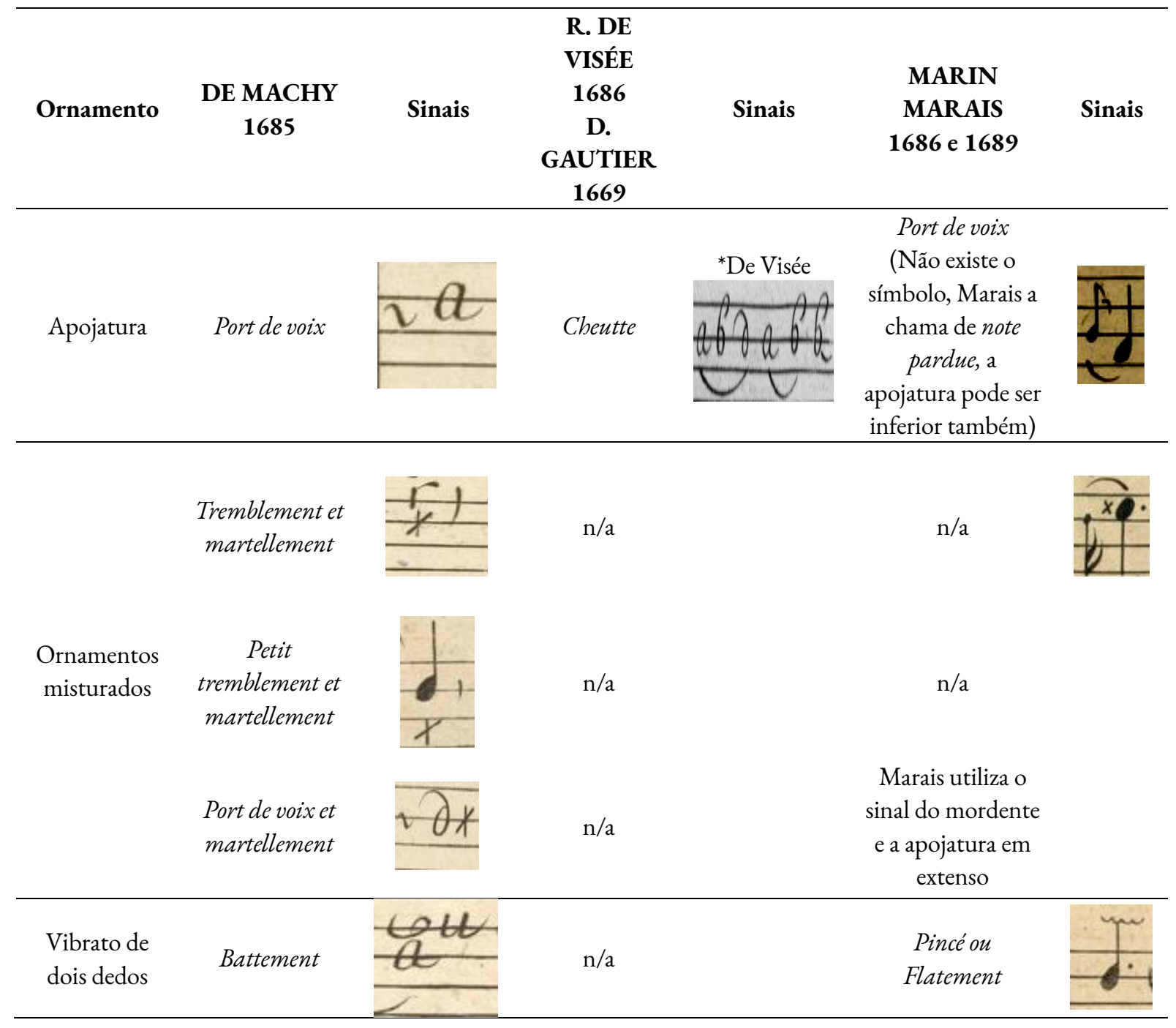

Fonte: O AUTOR (2020)

\section{Considerações finais}

A visão de De Machy sobre a viola da gamba já à época provocou divergências, e as ideias que constam em seu Avertissement não tiveram continuidade na geração seguinte de gambistas, o que inclui o seu modo de pensar e realizar a ornamentação. A ruptura com essa maneira de conceber a música para viola da gamba, fortemente inspirada na técnica dos instrumentos de cordas dedilhadas, contribuiu para o esquecimento de algumas práticas descritas por De Machy; estas eram de conhecimento de seus contemporâneos, mas para o gambista moderno são de difícil compreensão. 
A precisão com que De Machy grafou e explicou os seus símbolos de ornamentação é algo único, em comparação com outras publicações. Um exemplo desse esmero é a sutileza com a qual o gambista distingue o tremblement do petit tremblement; o que é um indicativo do cuidado e do refinamento que permeiam a sua obra.

As ornamentações de De Machy, assim como de outros músicos franceses do século XVII, podem ter diferentes formas de interpretação, principalmente aquelas raramente encontradas. Por isso, quanto maior o número de gambistas, instrumentistas de cordas dedilhadas, de outros instrumentos e cantores puderem apreciar e interpretar esse repertório, outras possibilidades de esclarecimentos serão possíveis.

\section{AGRADECIMENTOS}

Trabalho realizado com o apoio da Capes (Coordenação de Aperfeiçoamento de Pessoal de Nível Superior).

\section{REFERÊNCIAS}

CHAMBONNIÈRES, Jacques Campion. Les Pieces de Clavecin de Monsieur de Chambonnieres. Paris: 1670 .

CHENEY, Stuart. Dubuisson: a study of his music for solo bass viol. Tese (Doutorado). University of North Texas, 1988.

CHENEY, Stuart; COEYMAN, Barbara. The Viola da Gamba Family. KITE-POWELL, Jeffery. $A$ Performer's Guide to Seventeenth-Century Music. Indiana University Press, 2012.

CYR, Mary. "Dans le gout du theorbe": How did french viol players pluck the viol? Journal of the Viola da Gamba Society of America, v. 48, 2014.

CYR, Mary. Style and performance for bowed string instruments in French baroque music. Ashgate Publishing, Ltd., 2012.

DANOVILLE. L'Art de toucher le dessus et basse de Violle. Paris: Ballard, 1687

DE MACHY. Pièces de Violle en Musique et en Tablature. Paris: Ballard, 1685.

GREEN, Robert A. Jean Rousseau and Ornamentation in French Viol Music. Journal of the Viola da Gamba Society of America, v. 14, p. 4-41, 1977.

HOFFMANN, Bettina. The Viola da Gamba. New York: Routledge, 2018. 
KINNEY, Gordon J. Writings of the Viol by Dubuisson, DeMachy, Roland Marais and Étienne Loulié. Journal of the Viola da Gamba Society of America, v. 13, p. 19-57, 1976.

LESURE, François. Une querelle sur le jeu de la viole en 1688: J. Rousseau contre Demachy. Revue de musicologie, v. 46, n. 122, p. 181-199, 1960.

MARAIS, Marin. Pièces de Violes a une et deux violes. Paris: 1686.

MARAIS, Marin. Basse Continue des Pièces de Violes a une et deux violes. Paris: 1689.

NG, Shaun Kam Fook. Le Sieur de Machy and the French solo viol tradition. Dissertação (Mestrado). University of Western, Australia, 2008.

NG, Shaun Kam Fook. Ornamentation in Marin Marais Pieces de Viole. Tese (Doutorado). Universidade de Sydney/ Conservatório de Música, 2013.

ROLFHAMRE, Robin. French baroque lute music from 1650-1700. Dissertação (Mestrado). University of Agder, Noruega, 2010.

ROUSSEAU, Jean. Traite de la Viole. Paris: 1687.

ROUSSEAU, Jean. Réponce de Monsieur Rousseau. Paris: 1688.

VISÉE, Robert. Livre de Pieces de Guitarre. Paris: 1686.

SAINT-LAMBERT, Michel de. Les principes du clavecin. Paris: 1702.

SICARD, Michel. The French Viol School before 1650. Journal of the Viola da Gamba Society of America, v. 18, p. 76-93, 1981.

SICARD, Michel. The French Viol School: The Repertory from 1650 to Sainte-Colombe (ca. 1680). Journal of the Viola da Gamba Society of America. v.22, p. 42-55, 1985.

URQUHART, Margaret. Style and technique in the pieces de violes of Marin Marais. Tese (Doutorado), Universidade de Edimburgo, 1970.

\section{SOBRE OS AUTORES}

André Luiz Tartas é doutorando e Mestre em Musicologia (UFPR), e Licenciado em Educação Musical. Integrante do Laboratório de Música Antiga da UFPR (LAMUSA), onde atua como gambista e pesquisador da música francesa instrumental do século XVII e XVIII. Estudou violoncelo na EMBAP com Maria Alice Brandão, é professor de violoncelo e é aluno da gambista Kristina Augustin. ORCID: https://orcid.org/0000-0001-6314-8166. E-mail: andretartas@gmail.com

Silvana Scarinci é Professora da graduação e Pós-graduação em Música na UFPR. Alaudista, dirige o LAMUSA (Laboratório de Música Antiga da UFPR), responsável pelo resgate, edição e performance de obras raras do período barroco, como a ópera esquecida de Marin Marais, Ariane \& Bacchus. Publicou o livro e CD Safo Novella: uma poética do abandono nos lamentos de Barbara Strozzi (EDUSP e ALGOL editoras, 2008). Em 2014, foi finalista da Categoria 
TARTAS, André Luiz; SCARINCI, Silvana Ruffier; AUGUSTIN, Kristina. A Ornamentação na Viola da Gamba a partir da Visão de De Machy. Revista Vórtex, Curitiba, v.9, n.1, p. 1-26, 2021.

Cultura do Prêmio Claudia para mulheres de destaque na América Latina. Em 2017, realizou Estágio Sênior no Royal Birmingham Conservatoire, sob supervisão de Graham Sadler. ORCID: https//orcid.org/0000-0003-1933-7618. Email: silscarinci@gmail.com

Kristina Augustin é doutora em Música pela Universidade de Aveiro, mestre em Artes pela Universidade Estadual de Campinas (Unicamp-SP). Diplomou-se pelo Birmingham Conservatoire (UCE) e especializou-se em viola da gamba na Schola Cantorum Basiliensis (Suíça). Sua discografia conta com um LP e oito Cds com os grupos Música Antiga da UFF, Camerata Antiqua de Curitiba e Quadro Antiquo. Como fruto do trabalho de divulgação da viola da gamba recebeu a Moção de Aplausos da Câmara Municipal de Niterói e foi citada no dicionário Novo Aurélio, século XXI no verbete “viola da gamba" e introduziu a palavra "gambista" na língua portuguesa. ORCID: https://orcid.org/0000-0003-14357097. E-mail: krisaugustin@outlook.com 